\title{
Substrate Utilization by the Fetal Sheep Lung during the Last Trimester
}

\author{
REBECCA A. SIMMONS AND VALERIE E. CHARLTON \\ WITH THE TECHNICAL ASSISTANCE OF MICHAEL JOHENGEN \\ Division of Neonatology, Department of Pediatrics, CVRI, University of California, \\ San Francisco, California 94143
}

\begin{abstract}
In vivo substrate utilization has not been described for the maturing fetal lung. We, therefore, studied pulmonary delivery and use of major fetal substrates in six chronically catheterized fetal lambs over 119-141 days gestation. Oxygen, glucose, lactate, and $\alpha$-amino nitrogen concentrations were measured in the pulmonary artery and pulmonary vein whereas lung blood flow was determined using labeled microspheres. We found that lung oxygen availability and use increased near term. Oxygen delivery averaged $4960 \pm 480(\mathrm{SEM}) \mu \mathrm{l} / \mathrm{min}$ and rose with fetal age $(p<0.05)$; uptake averaged $708 \pm 111 \mu \mathrm{l} / \mathrm{min}$ and increased $93 \%$ near term $(p<0.05)$. In contrast, glucose availability and use fell with gestation. Pulmonary artery glucose decreased with time $(p<0.001)$, with a mean drop of $5.05 \pm 1.71 \mathrm{mg} / \mathrm{dl}$ in individual animals $(p<0.05)$. Average glucose uptake was $844 \pm 225 \mu \mathrm{g} / \mathrm{min}$ and fell near term $(p<0.05)$. Lactate was produced by the lung at a mean rate of $534 \pm 176 \mu \mathrm{g} / \mathrm{min}$; this did not change with gestation. Lung amino nitrogen availability increased with fetal age. Pulmonary artery amino nitrogen rose by 1.35 $\mathrm{mg} / \mathrm{dl}$, or $43 \%(p<0.001)$ and lung delivery of amino nitrogen increased $(p<0.05)$. The mean pulmonary glu$\operatorname{cose} / \mathrm{O}_{2}$ ratio was $1.48 \pm 0.26$ and decreased with gestation $(p<0.05)$, being $<1.0$ near term. The glucose-lactate $/ \mathrm{O}_{2}$ ratio was $0.67 \pm 0.26$, implying that $30 \%$ of lung oxidative metabolism is still unaccounted for. The alterations in delivery of substrates to the lung which were identified may serve as signals for pulmonary maturation, inducing the changes in lung metabolism that were found near term. (Pediatr Res 23: 606-611, 1988)
\end{abstract}

\section{Abbreviations}

PA, pulmonary artery

PV, pulmonary vein

FA, femoral artery

IVC, inferior vena cava

$\mathrm{G} / \mathrm{O}_{2}$, glucose/oxygen metabolic quotient

$\mathrm{G}-\mathrm{L} / \mathrm{O}_{2}$, glucose-lactate/oxygen metabolic quotient

Fetal substrate utilization in vivo has been investigated for several organs using the chronically catheterized fetal lamb as an animal model of undisturbed development in utero (1-5). However, no in vivo chronic studies have been carried out on the fetal lung.

Received October 13, 1987; accepted February 5, 1988

Correspondence and reprint requests Dr. Valerie E. Charlton, Division of Neonatology, Department of Pediatrics, Box 0748, University of California San Francisco, San Francisco, CA 94143.

Supported by HL SCOR 27356. V. E. C. is a recipient of an RCDA from NICHD. R. A. S. was supported by Training Grant HD-07162.
Using the chronically catheterized fetal sheep model (6), we determined the availability of major fetal substrates to the developing lung and lung substrate utilization during the third trimester. Pulmonary delivery and uptake of oxygen, glucose, lactate, and $\alpha$-amino nitrogen were followed over the last weeks of gestation, allowing us to define the changing pattern of pulmonary substrate availability and use that accompanies advancing gestation.

\section{METHODS}

Surgical preparation and recovery. Six mixed Western, breeddated, pregnant sheep of 115-125 days gestation were surgically prepared with indwelling catheters, using methods described previously (6). Six fetal lambs were catheterized, five singletons and one from a set of twins. Surgery was performed after the animals had fasted $24 \mathrm{~h}$. Spinal anesthesia was induced with 2.0 $\mathrm{ml}$ of $1 \%$ tetracaine hydrochloride and analgesia was provided with intravenous pentobarbital $(65 \mathrm{mg} / \mathrm{ml})$ as needed. Polyvinyl catheters $(0.050$ inch inner diameter and 0.090 inch outer diameter) were placed in the maternal femoral artery and vein. The uterus was then exposed through a midline abdominal incision and opened. Local anesthesia with $1 \%$ xylocaine was used for all fetal incisions; pentobarbital $(5-10 \mathrm{mg} / \mathrm{kg})$ and succinyl choline $(1 \mathrm{mg} / \mathrm{kg})$ were given as needed for fetal sedation and to minimize fetal movement. Catheters $(0.030$ inch inner diameter and 0.048 inch outer diameter) were inserted either into the fetal femoral artery and vein of one hindlimb (four animals) or into the carotid artery and jugular vein (two animals). The fetal chest was then exposed and a thoracic incision was made on the left side, from sternum to spine. The pleural space was entered through the fourth intercostal space and the lungs were gently retracted. The pericardium was opened and a $20-$ gauge Teflon catheter, fitted on a piece of polyvinyl tubing (7), was then placed into the main pulmonary artery. A catheter ( 0.011 inch inner diameter and 0.030 inch outer diameter) was inserted into a distal pulmonary vein and threaded up into a major vein draining the upper lobe of the left fetal lung. The fetal chest was then closed. A multipore amniotic fluid catheter was anchored in the uterus and the uterus was also sutured closed. All catheters were exteriorized through a stab wound in the maternal flank, where they were protected by a mesh pocket. At surgery, penicillin (1 million units) and kanamycin (200 mg) were given to the ewe intravenously and were also instilled into the amniotic cavity.

After surgery the ewes were fed ad libitum on alfalfa meal and water. They were accustomed to our laboratory environment by daily handling. Antibiotic administration, as described above, was repeated for 5 days after surgery and all catheters were flushed with heparin $(1000 \mathrm{U} / \mathrm{ml})$ daily.

Study protocol. After the initial recovery period, each animal was repetitively studied for pulmonary uptake of major substrates and pulmonary blood flow. Studies were carried out in the 
midday with the mothers in familiar movable pens. All studies reported herein were performed between 119 and 141 days gestation, at least 4 days after surgery, and at least 2 days before spontaneous delivery or fetal demise. All ewes and fetuses were in good health with fetal femoral or carotid arterial $\mathrm{pH}>7.30$.

At study, fetal blood samples were drawn simultaneously from the fetal pulmonary artery and pulmonary vein. Analyses were carried out for whole blood concentrations of glucose, lactate, total amino acids (measured as $\alpha$-amino nitrogen), $\mathrm{Hb}$, oxygen saturation, $\mathrm{pH}$, and $\mathrm{PaO}_{2}$. Two complete sets of metabolite and blood gas measurements were made and averaged to obtain a study value. The substrate and blood gas measurements were repeated one to two times weekly. Fetal pulmonary blood flow was measured with radiolabeled microspheres at the time of substrate sampling. Flow measurements were made in duplicate and averaged to obtain a study value.

A blood sample was also drawn from the maternal artery during each study. This was used to measure maternal metabolite levels and blood gases.

Repetitive studies in these animals spanned an average period of $14 \pm 2$ (SEM) days. Mean gestational age at delivery or death was $140 \pm 2$ days. At delivery fetal weight was obtained, and the lungs were collected and weighed. Thereafter, the lungs were carbonized and counted for radioactivity to calculate lung blood flow. Average birth weight of the fetuses studied was $3746 \pm 461$ $\mathrm{g}$, total lung wet weight averaged $81 \pm 14 \mathrm{~g}$, and the mean lung/ body weight ratio was $2.1 \pm 0.3 \%$; all values were within the normal range $(8-10)$. The wet weights of the instrumented left upper lobes of the lung in study animals were $12 \pm 2 \mathrm{~g}$, similar to the $13 \pm 2 \mathrm{~g}$ weight of left upper lobes in animals without pulmonary catheters in our laboratory.

Analytical methods. All metabolites were analyzed in whole blood, in duplicate. The deproteinization steps in the assays for glucose, lactate, and $\alpha$-amino nitrogen were carried out with iced reagents, immediately after blood drawing. The supernatant obtained was frozen at $-40^{\circ} \mathrm{C}$. After delivery, samples from repetitive studies on the same animal were thawed and analyzed together in the same assay run. Glucose concentration was analyzed by an enzymatic, colorimetric glucose oxidase method, lactate by a lactate dehydrogenase assay (both assays from Sigma Chemical Co., St. Louis, MO), and $\alpha$-amino nitrogen by a colorimetric method involving the combination of $\alpha$-amino nitrogen groups on amino acids with $\beta$-napthoquinone sulfonate $(11,12)$. Our mean percentage error between duplicate fetal samples was $1.8 \%$ for glucose, $1.5 \%$ for lactate, and $3.8 \%$ for $\alpha$ amino nitrogen.

Blood gases were measured immediately after blood drawing, on a Corning $158 \mathrm{pH} /$ blood gas analyzer (Corning Medical, Medford, MA). Hb concentration and oxgyen saturation were measured, in duplicate, on a Radiometer-Copenhagen OSM 2 hemoximeter (The London Co., Westlake, OH). Calibration of both machines was checked before each study. Our mean percentage error between duplicate measurements of $\mathrm{Hb}$ was $1.0 \%$ and for oxygen saturation it was $0.8 \%$.

Oxygen content was calculated using the formula (13):

$$
\begin{aligned}
\mathrm{O}_{2} \text { content } & =\left[1.34 \times \mathrm{Hb}(\mathrm{g} / \mathrm{dl}) \times \mathrm{O}_{2} \text { saturation }(\%)\right] \\
& +\left[0.003 \times \mathrm{PaO}_{2}(\mathrm{~mm} \mathrm{Hg})\right]
\end{aligned}
$$

The accuracy of this method for fetal blood has been verified (14).

Because of occasional laboratory error or difficulty with catheter sampling, blood samples were not always analyzed for every metabolite. Simultaneous PA-PV substrate differences also could not be obtained at the time of several lung blood flow measurements.

The percentage of pulmonary oxidative metabolism that could be accounted for by complete oxidation of glucose was calculated using the glucose to oxygen quotient. Inasmuch as $6 \mathrm{~mol}$ of moles oxygen are used during complete oxidative combustion of $1 \mathrm{~mol}$ of glucose to carbon dioxide and water, the ratio was calculated as:

$$
\frac{\text { glucose }}{\text { oxygen }}=\frac{6 \times \text { PA-PV glucose, } \mathrm{mM}}{\text { PA-PV oxygen, } \mathrm{mM}}
$$

The percentage of oxidative metabolism that could be accounted for by glucose oxidation, in the face of pulmonary lactate production from glucose, was calculated as the (glucose-lactate) to oxygen quotient. Because each mole of glucose produces $2 \mathrm{~mol}$ of lactate, this was calculated as:

\section{glucose-lactate}

oxygen

$$
=\frac{6 \times[\mathrm{PA}-\mathrm{PV} \text { glucose, } \mathrm{mM}-(\mathrm{PV}-\mathrm{PA} \text { lactate, } \mathrm{mM} / 2)]}{\mathrm{PA}-\mathrm{PV} \text { oxygen, } \mathrm{mM}}
$$

Delivery of nutrients and oxygen to the lung was calculated as PA concentration times pulmonary blood flow. Uptake by the lung was calculated by multiplying the PA-PV concentration difference times pulmonary blood flow. For purposes of calculating substrate uptake, blood draining the left upper pulmonary lobe was assumed to be representative of blood draining the lung as a whole.

Blood flow to the lungs was measured using $15 \mu \mathrm{m}$ in diameter radiolabeled microspheres (New England Nuclear, Boston, MA). The microspheres were injected into the fetal inferior vena cava (through the femoral vein) or into the superior vena cava (through the jugular vein), while a reference sample was simultaneously withdrawn from the PA at a constant rate. Blood flow was calculated using the following formula (6):

pulmonary arterial blood flow $(\mathrm{ml} / \mathrm{min})$ radioisotope counts in lungs

radioisotope counts in reference sample $\times$ PA reference sample flow $(\mathrm{ml} / \mathrm{min})$

Most of the microspheres injected into the IVC will reach the fetal lungs through the pulmonary artery. Because a small number of IVC-injected spheres will also reach the lungs through the bronchial circulation, we determined whether omission of bronchial flow would have a measurable effect on our calculation of lung blood flow and substrate uptake. During six studies in two animals, microspheres carrying a different radiolabel were injected through the PV, while pulmonary arterial blood flow measurements were made. A second reference sample was simultaneously drawn from the FA. Microspheres injected into the PV will pass into the left side of the heart and then into the aortic arch and descending aorta. They will reach the lungs only through the bronchial arteries; these come off the bronchoesophageal trunk from the descending aorta in the sheep (15). Using lung counts of the PV-injected radiolabeled spheres and the FA reference sample, bronchial flow was calculated as described for pulmonary flow above. Then, using the bronchial flow and the concentration of IVC-injected labeled spheres in the FA reference sample, we could determine the quantity of IVC-injected microspheres reaching the lungs through the bronchial circulation. After subtracting the bronchially derived spheres from the lung isotope counts of IVC injected spheres, corrected calculation of actual pulmonary blood flow was made. Total lung blood flow was determined as corrected pulmonary flow + bronchial flow.

Bronchial flow was found to average $14 \pm 3 \%(n=6)$ of total lung flow. Measurements of total lung flow differed from uncorrected pulmonary blood flow measurements by only $5 \pm 1 \%$ ( $n$ $=6$ ). This was because the overestimate of pulmonary flow in uncorrected measurements was essentially equal to bronchial flow. Nonsignificant differences of $6 \pm 1 \%$ were found between substrate uptakes calculated as either (PA-PV substrate difference $X$ corrected PA flow) + (FA-PV substrate difference $\times$ bronchial flow) versus uptake calculated as (PA-PV substrate difference $\times$ uncorrected pulmonary blood flow). The latter calculation was, therefore, used for all studies presented herein. 
Statistical analysis. All data are expressed as the mean \pm SEM. Comparisons within the same animals, with respect to changes in substrate levels over time and PA-PV substrate differences were made using the paired $t$ test (16). The unpaired $t$ test was used when comparisons were made using data from different animals (16). Relationships between gestational age and substrate metabolism and between the different substrates was defined using the correlation coefficient and regression analysis, by the least squares method (16). A $p$ value of $\leq 0.05$ was accepted as demonstrating a significant difference or correlation.

\section{RESULTS}

Over the 3-wk study period (119-141 days gestation), pulmonary blood flow was found to increase as gestation advanced ( $r$ $=0.40, n=25, p<0.05$ ). Measurements of pulmonary blood flow made over the first week of this period ( $\leq 127$ days gestation) was $64 \pm 12 \mathrm{ml} / \mathrm{min}(n=7)$, which was significantly different from the average flow of $110 \pm 15 \mathrm{ml} / \mathrm{min}(n=9)$ measured during the last week in maturing fetuses $(\geq 134$ days $)(p<0.05)$.

In pulmonary arterial blood perfusing the fetal lung, the $\mathrm{PaO}_{2}$ averaged $19.3 \pm 3.7 \mathrm{~mm} \mathrm{Hg}$, the mean $\mathrm{PaO}_{2}$ saturation was 41.3 $\pm 1.5 \%, \mathrm{Hb}$ content was $9.5 \pm 0.3 \mathrm{~g} / \mathrm{ll}$, and PA oxygen content was $5.25 \pm 0.19 \mathrm{ml} / \mathrm{dl}$ (for all $n=36$ ). There was no change in PA $\mathrm{PaO}_{2}$, oxygen saturation, or oxygen content with gestational age, but $\mathrm{Hb}$ concentration did increase with fetal gestation $(r=$ $0.34, n=36, p<0.05$ ).

Delivery of oxygen to the lungs averaged $4.96 \pm 0.48 \mathrm{ml} / \mathrm{min}$ $(n=25)$ and increased with gestation (Fig. 1). In observations made during the last week ( $\geq 134$ days), oxygen delivery averaged $6.15 \pm 0.76 \mathrm{ml} / \mathrm{min}(n=9)$, compared to $4.29 \pm 0.54 \mathrm{ml} / \mathrm{min}$ $(n=16)$ for observations made at younger gestations ( $<134$ days) $(p<0.05)$.

Oxygen uptake was documented across the pulmonary circulation in 24 of 25 paired PA-PV differences; one difference was zero. The mean PA-PV oxygen content difference was $818 \pm 90$ $\mu \mathrm{l} / \mathrm{dl}(n=25, p<0.001)$ and this did not change as the fetus matured. For those measurements where simultaneous blood flow was available, oxygen uptake averaged $708 \pm 111 \mu \mathrm{l} / \mathrm{min}$ $(n=15)$ or $17 \pm 2 \%(n=15)$ of pulmonary oxygen delivery. Oxygen uptake correlated significantly with oxygen delivery to the lungs (Fig. 2) and increased with gestation. Oxygen uptake averaged $494 \pm 104 \mu \mathrm{l} / \mathrm{min}(n=8)$ in observations made at $<134$ days gestation compared to $952 \pm 168 \mu \mathrm{l} / \mathrm{min}(n=7)$ for observations made at $\geq 134$ days $(p<0.05)$.

The average concentration of glucose in the PA over the study period was $19.42 \pm 0.90 \mathrm{mg} / \mathrm{dl}(n=36)$. Interestingly, the

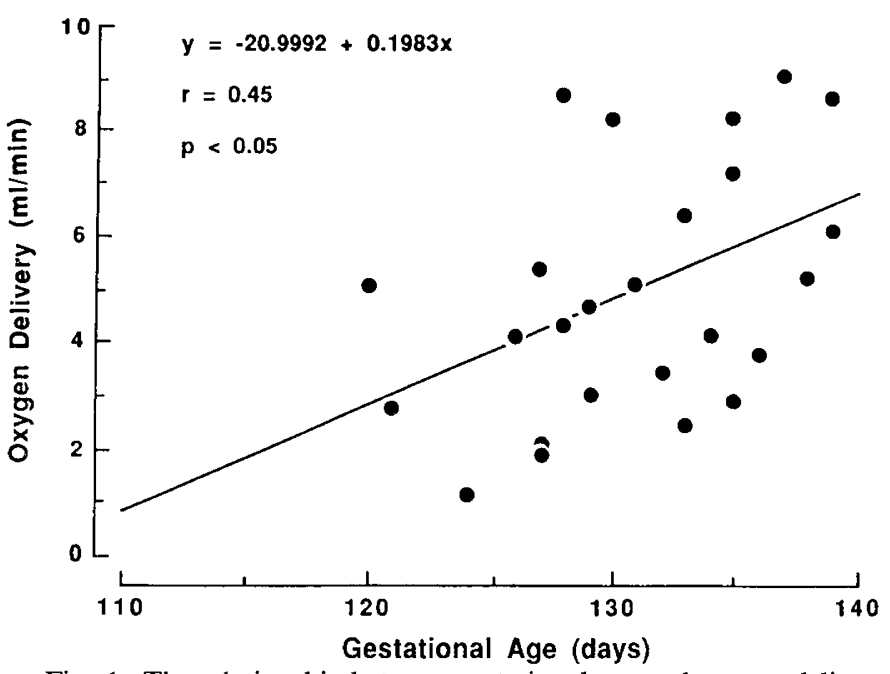

Fig. 1. The relationship between gestational age and oxygen delivery to the lung.

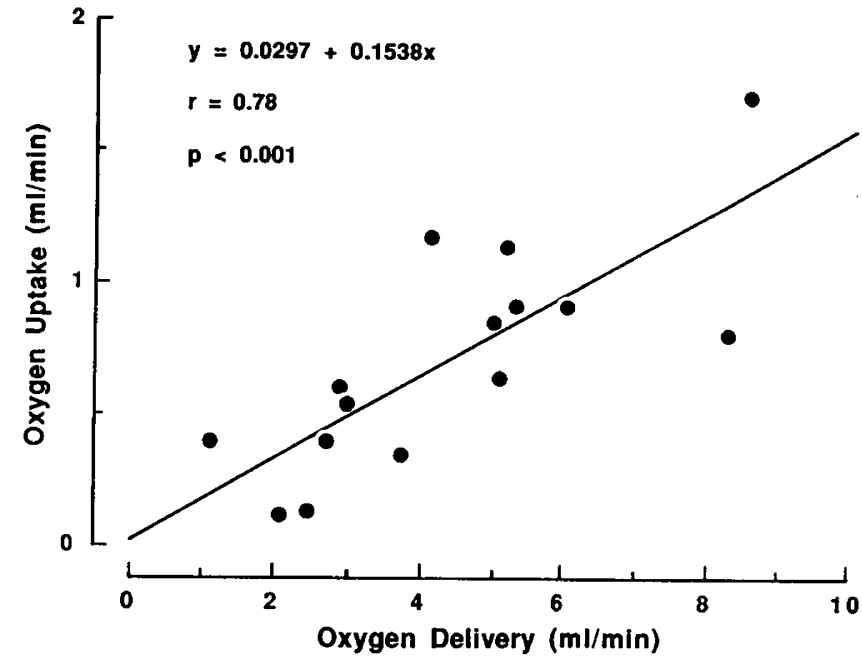

Fig. 2. The relationship between oxygen delivery and oxygen uptake by the lung.

concentration of PA glucose fell as gestation advanced. This relationship is shown in Figure 3. Measurements of PA glucose made before 134 days averaged $20.74 \pm 4.81 \mathrm{mg} / \mathrm{dl}(n=23)$, compared to $17.09 \pm 4.10 \mathrm{mg} / \mathrm{dl}$ for measurements made at or after 134 days $(n=13)(p<0.05)$. Within individual animals, the mean difference between initial PA glucose values and final values near delivery was $5.05 \pm 1.71 \mathrm{mg} / \mathrm{dl}(n=6, p<0.05)$, falling from $23.40 \pm 2.46 \mathrm{mg} / \mathrm{dl}$ at $119-126$ days to $18.35 \pm$ $4.69 \mathrm{mg} / \mathrm{dl}$ at $133-141$ days. This change was not due to alterations in maternal glucose which remained stable at $57.44 \pm 3.86$ $\mathrm{mg} / \mathrm{dl}$ at $119-126$ days versus $54.83 \pm 1.78 \mathrm{mg} / \mathrm{dl}$ at $133-141$ days.

During the weeks of study, delivery of glucose to the fetal lung averaged $16.56 \pm 1.73 \mathrm{mg} / \mathrm{min}(n=25)$. Glucose delivery did not change with gestation because the decrease in glucose concentration was balanced by the increase in pulmonary flow.

Glucose was found to be taken up by the fetal lung in large amounts. Glucose content was higher in the PA compared to the $\mathrm{PV}$ in 24 of 26 samples, with a mean glucose difference of 1.31 $\pm 0.20 \mathrm{mg} / \mathrm{dl}(n=26, p<0.001)$. This difference tended to decrease with advancing gestation $(n=26, r=0.38, p<0.1)$. For those observations where blood flow was available, pulmonary glucose uptake averaged $844 \pm 225 \mu \mathrm{g} / \mathrm{dl}(n=15)$ and equaled $8 \pm 1 \%(n=15)$ of glucose delivery. Of note was the fact that lung glucose uptake decreased as the fetus approached term; this relationship is graphed in Figure 4.

The average concentration of lactate in the PA was $15.04 \pm$ $0.42 \mathrm{mg} / \mathrm{dl}(n=36)$ which did not change as the fetus matured. Lactate delivery to the lung averaged $13.8 \pm 1.5 \mathrm{mg} / \mathrm{min}(n=$ $25)$ and also did not change with gestation.

In contrast to pulmonary uptake of glucose, lactate was produced by the lung. The PA-PV difference in lactate was positive in 25 of 26 samples. The mean PV-PA difference was $787 \pm 16$ $\mu \mathrm{g} / \mathrm{dl}(n=26, p<0.001)$, and in observations where blood flow was measured, production of lactate averaged $534 \pm 176 \mu \mathrm{g} / \mathrm{min}$ $(n=15)$. Neither the PV-PA difference nor lactate production changed over time. Where glucose uptake across the lung was simultaneously documented, lactate production would have accounted for $50 \pm 16 \%$ of glucose uptake $(n=13)$, assuming that lactate was derived from glucose.

The average PA $\alpha$-amino nitrogen was $8.81 \pm 0.22 \mathrm{mg} / \mathrm{dl}(n$ $=36$ ) and amino nitrogen was noted to increase with gestation. PA $\alpha$-amino nitrogen in observations made at $<134$ days was $8.32 \pm 0.21 \mathrm{mg} / \mathrm{dl}(n=23)$, compared to $9.67 \pm 0.39 \mathrm{mg} / \mathrm{dl}(n$ $=13$ ) in observations made at $\geq 134$ days $(p<0.001)$. Delivery of $\alpha$-amino nitrogen to the lung averaged $8.21 \pm 0.78 \mathrm{mg} / \mathrm{min}$ 


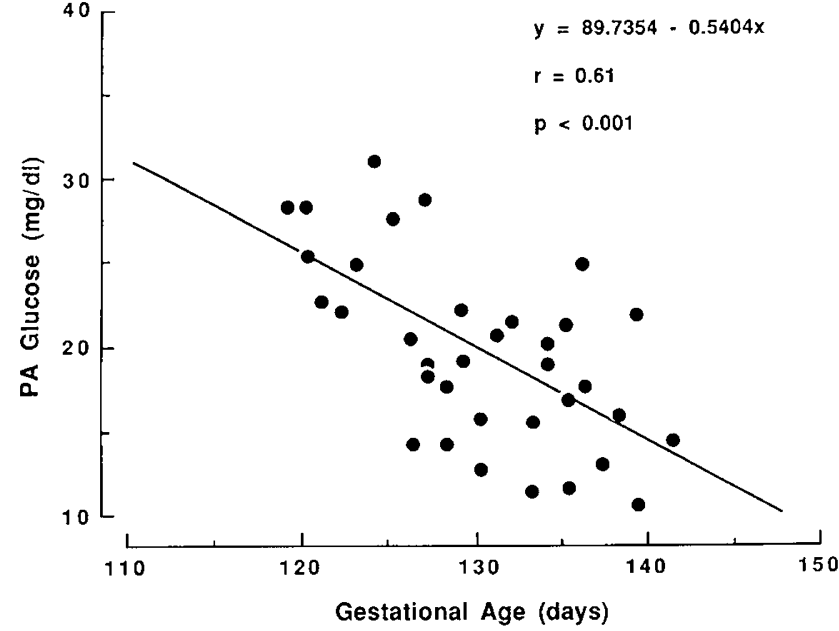

Fig. 3. The relationship between gestational age and PA glucose.

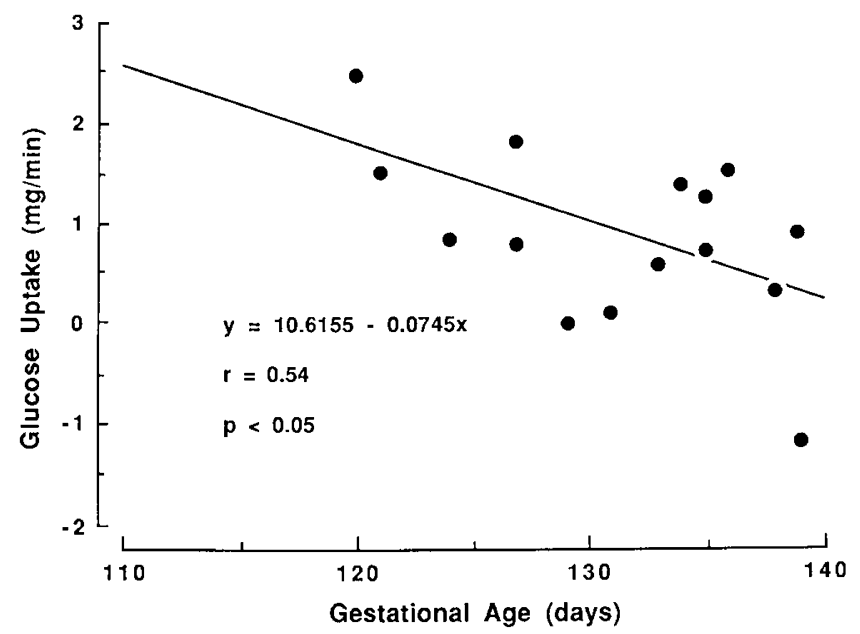

Fig. 4. The relationship between gestational age and glucose uptake across the lung.

during the weeks of study and increased significantly as gestation advanced (Fig. 5). PA $\alpha$-amino nitrogen delivery before 134 days averaged $7.00 \pm 0.76 \mathrm{mg} / \mathrm{min}(n=16)$ compared to $10.37 \pm$ $1.49 \mathrm{mg} / \mathrm{min}(n=9)$ near term, after 134 days $(p<0.05)$. No loss or production of $\alpha$-amino nitrogen could be demonstrated across the lung. The mean PA-PV difference for $\alpha$-amino nitrogen was $2200 \pm 1960 \mu \mathrm{g} / \mathrm{dl}(n=25)$, which was not different from zero.

Lung extractions of glucose and oxygen were compared, using the $\mathrm{G} / \mathrm{O}_{2}$ ratio. The average $\mathrm{G} / \mathrm{O}_{2}$ was found to be $1.48 \pm 0.26$ $(n=24$, excluding the one sample where PA-PV oxygen was zero). The $\mathrm{G} / \mathrm{O}_{2}$ ratio declined as gestation advanced (Fig. 6) averaging $2.21 \pm 1.08(n=10)$ during the first week at $\leq 127$ days, compared to $1.06 \pm 0.35(n=10)$ at $\geq 134$ days $(p<0.05)$. During the last week of study, seven of $10 \mathrm{G} / \mathrm{O}_{2}$ ratios were $<1.0$ and over the last 4 days the $\mathrm{G} / \mathrm{O}_{2}$ averaged $0.58(n=4)$.

When lactate production was subtracted from glucose uptake, the resultant $\mathrm{G}-\mathrm{L} / \mathrm{O}_{2}$ ratio was found to average $0.67 \pm 0.26$ ( $n$ $=24)$. There was no correlation between gestational age and $\mathrm{G}-\mathrm{L} / \mathrm{O}_{2}$.

\section{DISCUSSION}

The aims of this study were to identify the major substrates used by the lung during the last trimester of gestation and to define the metabolic changes that occur in the maturing lung in

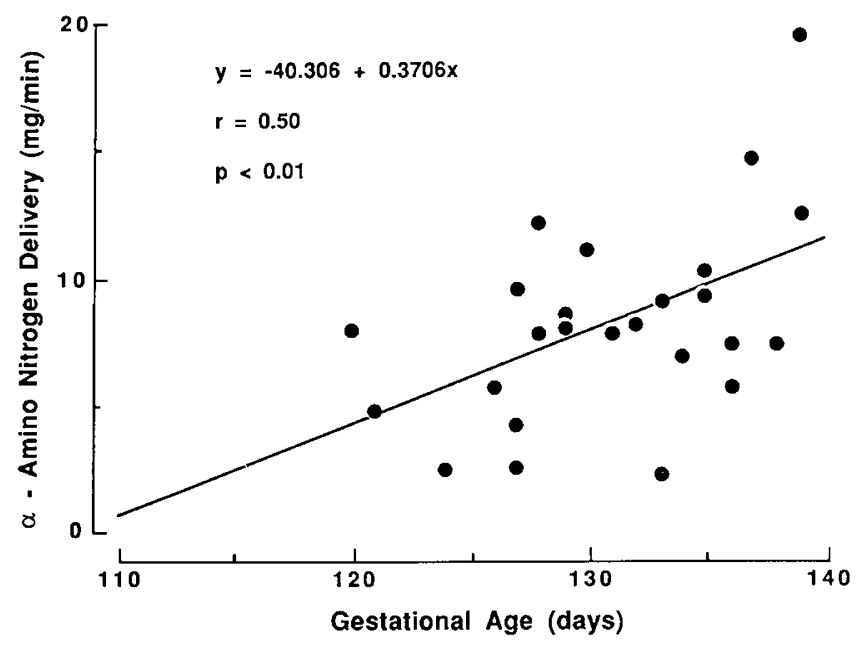

Fig. 5. The relationship between gestational age and $\alpha$-amino nitrogen delivery to the lung.

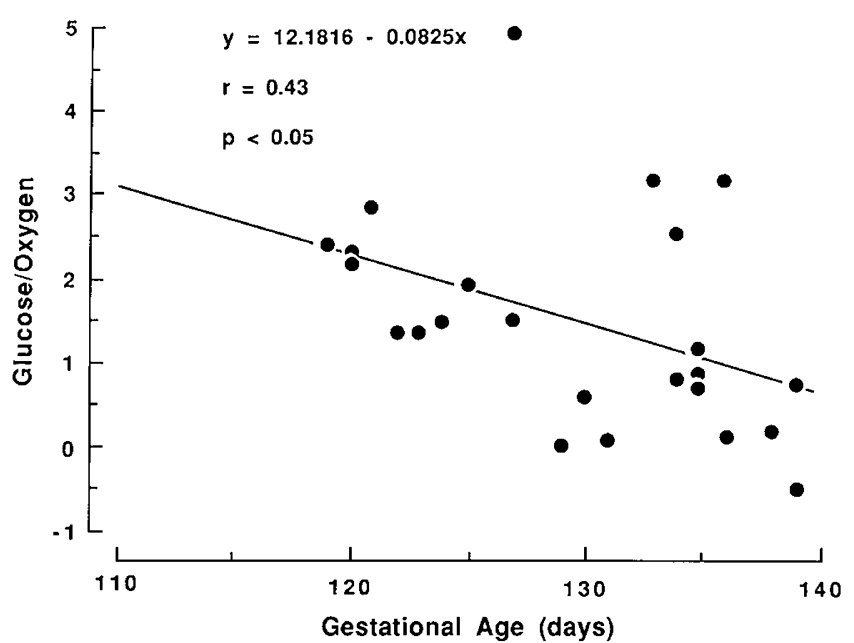

Fig. 6. The relationship between gestational age and the lung.

vivo. Our results indicate that the fetal lung is metabolically active, using oxygen and glucose and producing lactate. Pulmonary substrate availability and utilization are not static and change with advancing gestation. Observations made in fetuses of 134 days or more showed significant differences in lung metabolism compared to younger animals. This is of interest because maturation of the lung in the sheep occurs at 134 to 135 days gestation as indicated by increased surfactant availability, disappearance of lung glycogen, and increase in lung distensibility $(17-21)$.

In the third trimester fetal lamb, the lung consumed $708 \pm$ $111 \mu \mathrm{g} / \mathrm{min}$ of oxygen, or approximately $4 \%$ of the total quantity of oxygen taken up across the placenta (8). The average oxygen uptake at and after 134 days gestation was $93 \%$ more than the average oxygen uptake found in younger fetuses of 120 to 134 days gestation. Oxygen delivery also increased $43 \%$ over the same period, with oxygen uptake closely correlated with delivery. Over the gestational period studied, lung weight increases only $24 \%$ (10, 22; Simmons RA, Charlton VE, personal observations). Oxygen delivery and utilization are, therefore, increasing more rapidly than lung size, resulting in an actual increase in oxygen availability and utilization per unit weight of fetal lung near term.

Glucose was found to be a major oxidative substrate in the lung, as has been reported for the total fetus and individual organs $(1,2,5,23)$. However, unlike oxygen, availability of 
glucose to the lungs decreased as the fetus matured. Pulmonary arterial glucose concentration fell over the period of study. Measurements made at $\geq 134$ days gestation averaged $18 \%$ lower than those made in younger fetuses and a decrease of $28 \%$ was found between initial and final studies in individual animals. The decline in glucose concentration was similar to, but of greater magnitude than, those previously found in femoral artery samples from fetal sheep over the last weeks of gestation $(8,9)$.

Glucose delivery to the lungs remained static over the final weeks of the third trimester; the decrease in pulmonary artery glucose was balanced by an increase in pulmonary blood flow. However, because lung size was increasing, glucose delivery per unit of lung weight actually declined during this period. The average glucose uptake by the lung was $844 \pm 225 \mu \mathrm{g} / \mathrm{min}$, or $5 \%$ of the total glucose taken up across the placenta (8), but concomitant with the decline in glucose availability near term, utilization of glucose fell. Inasmuch as pulmonary oxygen delivery and oxidative metabolism were found to be increasing over the period, the decrease in pulmonary glucose use noted was not due to any deterioration of our fetal preparations. Furthermore, the fall in fetal pulmonary glucose concentration was not due to any change in maternal glucose levels, which were stable during the study period. We suggest that the observed decrease in glucose concentration and availability per unit of lung weight may serve as a physiologic signal, which leads to metabolic changes in the lung that are part of the normal maturational process. In situations where glucose delivery to the lung remains high near term, metabolic maturation of the fetal lung may be compromised. This is supported by the observation that fetal hyperglycemia is implicated as a major etiologic factor in the pathogenesis of the respiratory distress syndrome (leading to decreased surfactant availability) in the infants of diabetic mothers $(24,25)$. Further, in vitro studies have described a much greater lung utilization of glucose in fetal animals than in newborn and older animals (26).

The fetus as a whole is known to be a net consumer of lactate, because there is fetal uptake of lactate from the placenta via the umbilical circulation (27). However, lactate is also produced within the fetus at high rates (28). Our study demonstrates that the fetal lung is one of the organs that normally produce lactate. Conversion of glucose to lactate has been demonstrated by radiolabeled glucose infusions in the sheep $(28,29)$ and in type II fetal pneumocytes in vitro (30). Most likely fetal pulmonary lactate is being derived from glucose and the high rate of lactate production would account for $50 \%$ of pulmonary glucose uptake. Our in vivo findings in the sheep are in agreement with in vitro studies performed on isolated fetal type II pneumocytes. High rates of lactate production were also found in the fetal pneumocytes, with lactate synthesis accounting for $79 \%$ of cellular glucose utilization (30).

Although the fetus as a whole uses and catabolizes amino acids $(31,32)$, we could not detect a significant uptake of total amino acids (measured as amino nitrogen) across the lung. However, the quantity of amino acids reaching the lung increased significantly as gestation advanced. The concentration of total amino acids in the pulmonary artery increased by $16 \%$ in fetuses $\geq 134$ days compared to younger animals. Similar percentage increases in femoral arterial amino acid concentration have been previously noted in the fetal lamb close to term $(8,9)$. With the increase in pulmonary blood flow, amino acid delivery to the lung was $48 \%$ more during the last week of gestation than earlier. Inasmuch as amino acid delivery increased more rapidly than lung weight, availability of total amino acids per unit lung weight rose. Whether increased total amino acid availability is necessary for the developing lung is unclear. It is possible that amino acids serve as signals for as yet unidentified structural changes or for lung growth (22). We were unable to demonstrate pulmonary utilization of total amino acids, but uptake of small quantities of amino acids for protein synthesis or oxidative catabolism would have been missed by our methods. Further, changes in delivery or uptake of specific amino acids were not evaluated.
A substrate to oxygen quotient is an expression of the proportion of total oxygen uptake that can be accounted for if a substrate is completely oxidized to carbon dioxide and water. The umbilical $\mathrm{G} / \mathrm{O}_{2}$ ratio in the fetal sheep has been reported as 0.41 to $0.57(8,33)$. This indicates that the amount of glucose taken up by the total fetus is less than the amount of substrate needed to sustain fetal energy metabolism and other metabolites such as amino acids and lactate are also used to fuel oxidative metabolism $(27,31)$. However, several individual fetal organs take up large quantities of glucose, which totally account for or even exceed their fuel needs for oxidative metabolism. Examples are the hindlimb $\left(\mathrm{G} / \mathrm{O}_{2}\right.$ of 1.2$)$ and the brain $\left(\mathrm{G} / \mathrm{O}_{2}\right.$ of 1.0$)(4,34)$.

We found that the $\mathrm{G} / \mathrm{O}_{2}$ in the fetal lung averaged 1.48 , indicating that if all the glucose taken up by the lung were oxidized to carbon dioxide and water, glucose uptake would more than account for pulmonary oxygen consumption. As gestation advanced, however, this ratio fell to less than one, indicating that near term complete oxidation of glucose could not account for lung oxidative metabolism. Further, a large fraction of the glucose taken up throughout the third trimester is probably not being oxidized because the lung is also producing a large amount of lactate. Corrected for lactate production, the pulmonary $\mathrm{G}-\mathrm{L} / \mathrm{O}_{2}$ ratio was approximately 0.70 . This implies that more than $30 \%$ of fetal pulmonary oxidative metabolism still remains unidentified. Other possible substrates need to be investigated.

In summary, the fetal lung consumes large amounts of glucose relative to its oxygen consumption and produces lactate. However, more than $30 \%$ of the substrate burned oxidatively by the lung is unidentified. There are significant differences in lung metabolism as gestation progresses. Pulmonary oxygen delivery and uptake increase, glucose availability and uptake decrease, and amino acid availability increases. These changes in substrate availability may serve as signals for maturation of the fetal lung, with the increase in oxidative metabolism and decrease in glucose utilization indicative of the metabolic changes accompanying maturation.

\section{REFERENCES}

1. Jones MD, Burd LI, Makowski EL, Meschia G, Battaglia FC 1975 Cerebral metabolism in sheep: a comparative study of the adult, the lamb, and the fetus. Am J Physiol 229:235-239

2. Charlton V, Reis B, Lofgren D 1979 Consumption, rather than gain, of carbohydrates, amino acids, and oxygen across intestinal circulation in chronically catheterized fetal lambs. J Dev Physiol 1:329-336

3. Fisher DJ, Heymann MA, Rudolph AM 1980 Myocardial oxygen and carbohydrate consumption in fetal lambs in utero and in adult sheep. Am J Physiol 238:H399-H405

4. Bristow J, Rudolph AM, Itskovitz J, Barnes R 1983 Hepatic oxygen and glucose metabolism in the fetal lamb. Response to hypoxia. J Clin Invest 71:1047-1061

5. Iwamoto HS, Oh W, Rudolph AM 1985 Renal metabolism in fetal and newborn sheep. Pediatr Res 19:641-644

6. Rudolph AM, Heymann MA 1980 Methods for studying the circulation in utero. In: Nathanielsz PW (ed) Animal Models in Fetal Medicine I. Elsevier/ North, Holland, pp 1-57

7. Iwamoto H, Rudolph AM, Bristow J 1984 Fetal organ metabolism-techniques for catheterization of renal, pulmonary and hepatic veins in sheep. In: Nathanielsz P (ed) Monographs in Fetal Physiology 5: Animal Models in Fetal Medicine IV. Ithaca, New York, Perinatology Press, pp 1-18

8. Charlton V, Johengen M 1985 Effects of intrauterine nutritional supplementation on fetal growth retardation. Biol Neonate 48:125-142

9. Charlton V, Johengen M 1987 Fetal intravenous nutritional supplementation ameliorates the development of embolization-induced growth retardation in sheep. Pediatr Res 22:55-61

10. Barcroft J 1946 Growth of the body and its constituent parts. In: Researches on Pre-Natal Life. Blackwell Scientific, Oxford, pp 29-41

11. Frame CG, Russell JA, Wilhemi AE 1943 The colorimetric estimation of amino nitrogen in blood. J Biol Chem 149:255-270

12. Russell JA 1944 Note on the colorimetric determination of amino nitrogen. J Biol Chem 150:467-468

13. Comroe J 1975 The transport of oxygen by blood. In: The Physiology of Respiration. Yearbook Medical, Chicago, pp 183-196

14. McKinney RJ, Harris EA 1978 Evaluation of the $\mathrm{OSM}_{2}$ hemoximeter. Cardiovasc Res 12:630-634

15. May NDS 1977 The Anatomy of the Sheep. University of Queensland Press, St. Lucia, Queensland 
16. Zar JH 1984 Biostatistical Analysis. Prentice-Hall, Inc., Englewood Cliffs, NJ

17. Kitterman JA, Liggins GC, Campos GA 1981 Prepartum maturation of the lung in fetal sheep: relation to cortisol. J Appl Physiol 51:384-390

18. Perelman RH, Engle MJ, Kemnitz JW, Kotas RV, Farrell PM 1982 Biochemical and physiological development of fetal rhesus lung. J Appl Physiol 53:230-236

19. Mescher EJ, Platzker ACG, Ballard PL, Kitterman JA, Clements JA, Tooley WH 1975 Ontogeny of tracheal fluid, pulmonary surfactant and plasma corticoids in the fetal lamb. J Appl Physiol 39:1017-1021

20. Walters DV, Olver RE 1978 The role of catecholamines in lung liquid absorption at birth. Pediatr Res 12:239-242

21. Benson BJ, Kitterman JA, Clements JA, Mescher EJ, Tooley WH 1983 Changes in phospholipid composition of lung surfactant during developments of the fetal lamb. Biochim Biophys Acta 753:83-88

22. Schellenberg JC, Liggins GC 1987 Elastin and collagen in the fetal sheep lung. I. Ontogenesis. Pediatr Res 22:335-338

23. Battaglia FC, Meschia G 1978 Principal substrates of fetal metabolism. Physiol Rev 58:499-527

24. Warburton D 1983 Chronic hyperglycemia reduces surface active material flux in tracheal fluid of fetal lambs. J Clin Invest 71:550-555

25. Bourbon JR, Farrell PM 1985 Fetal lung development in the diabetic pregnancy. Pediatr Res 19:253-267

26. Hamosh M, Schechter Y, Hamosh P 1978 Metabolic activity of developing rabbit lung. Pediatr Res 12:95-100

27. Charlton Char V, Creasy RK 1976 Lactate and pyruvate as fetal metabolic substrates. Pediatr Res 10:231-234

28. Sparks JW, Hay WW, Bonds D, Meschia B, Battaglia FC 1982 Simultaneous measurements of lactate turnover rate and umbilical lactate uptake in the fetal lamb. J Clin Inves 70:179-192

29. Hay WW, Sparks JW, Quissell BJ, Battaglia FC, Meschia G 1981 Simultaneous measurements of umbilical uptake, fetal utilization rate, and fetal turnover rate of glucose. Am J Physiol 240:E662-E668

30. Engle MJ, Brown DJ, Dehring AF 1986 Lactate metabolism in fetal type II pneumocytes. Lung 164:155-164

31. Lemons JA, Schreiner RL 1983 Amino acid metabolism in the ovine fetus. Am J Physiol 244:E459-E466

32. Gresham EL, James EJ, Raye JR, Battaglia FC, Makowski EL, Meschia G 1972 Production and excretion of urea by the fetal lamb. Pediatrics 50:372379

33. James EF, Raye JR, Gresham EL, Makowski EL, Meschia G, Battaglia FC 1972 Fetal oxygen consumption, carbon dioxide production, and glucose uptake in a chronic sheep preparation. Pediatrics 50:361-370

34. Singh S, Sparks JW, Meschia G, Battaglia FC, Makowski EL 1984 Comparison of fetal and maternal hind limb metabolic quotients in sheep. Am J Obstet Gynecol 149:441-449 